\title{
MODEL PEMBELAJARAN TREFFINGER: PENGARUH PENERAPAN TERHADAP HASIL BELAJAR FISIKA MATERI KALOR
}

\author{
Eka Syiam Sholekhah ${ }^{1 *}$, Siti Anisatur Rofiqah ${ }^{1}$, Effendi $^{1}$ \\ Program Studi Pendidikan Fisika STKIP Nurul Huda Sukaraja \\ *Coressponding author: syamsoleheka@gmail.com
}

Article History:

Received: juli 13, 2020

Revised: oktober 19, 2020

Accepted: november 25, 2020

Published: desember 19, 2020

Keywords: $\quad$ Model

Treffinger, Hasil Belajar

Fisika, Materi Kalor

\begin{abstract}
The purpose of this study was to determine the effect of the application of the Treffinger learning model on student physics learning outcomes on heat topic in class VII SMP NU Tebat Jaya in the 2019/2020 school year. This research was an experimental research design with Posttest Only Control Group Design. The samples of this research were 28 students of class VII A and 28 students of VII B. The data collection method in this study was a multiple-choice test method. The data analysis used was a statistical test using the t test statistical formula. Based on data analysis using the t-test, it was concluded that there was a significant effect of the application of the Treffinger learning model on students' physics learning outcomes on heat topic in class VII SMP NU Tebat Jaya in the 2019/2020 learning year with tcount 5.45 and ttable 1, 99.
\end{abstract}

\begin{abstract}
Abstrak: Tujuan penelitian ini adalah mengetahui pengaruh penerapan model pembelajaran Treffinger terhadap hasil belajar fisika siswa pada materi pembelajaran kalor di kelas VII SMP NU Tebat Jaya Tahun Pembelajaran 2019/2020. Penelitian ini jika dilihat tingkat eksplanasi termasuk penelitian eksperimen dengan desain Posttest Only Control Group Design. Sampel penelitian ini adalah siswa kelas VII A yang berjumlah 28 siswa dan kelas VII B yang berjumlah 28 siswa. Metode pengumpulan data dalam penelitian ini adalah metode tes pilihan ganda. Adapun analisis data yang digunakan adalah uji statistik dengan menggunakan rumus statistik uji t. Berdasarkan analisis data menggunakan uji t-tes disimpulkan bahwa terdapat pengaruh penerapan model pembelajaran Treffinger yang signifikan terhadap hasil belajar fisika siswa pada materi pembelajaran kalor di kelas VII SMP NU Tebat Jaya Tahun Pembelajaran 2019/2020 dengan nilai thitung 5,45 dan ttabel 1,99.
\end{abstract}

\section{PENDAHULUAN}

Pendidikan merupakan suatu hal yang sangat penting dalam kehidupan (Izzah, Sudarmin, Prasetyo, \& Wiyanto, 2020; Seifan, Robertson, \& Berenjian, 2020). Usaha sadar yang dirancang untuk mencapai tujuan yang ditetapkan disebut pendidikan. Tujuanya untuk meningkatkan kualitas sumber daya manusia dan untuk memajukan kehidupan bangsa yang lebih baik. Melalui proses pendidikan diharapkan menghasilkan siswa yang berkualitas sebagai generasi bangsa yang memiliki kemampuan intelektual tinggi dan berkepribadian yang utuh, beriman, dan bertakwa kepada Tuhan Yang Maha Esa (Undang-Undang Republik Indonesia, 2003).

Berbagai upaya telah dilakukan untuk meningkatkan kualitas pembelajaran di sekolah, antara lain dengan perbaikan kurikulum (Dameron, Camp, Friedmann, \& Parikh-foxx, 2020). Kurikulum sebagai pedoman untuk melakukan suatu pembelajaran di sekolah. Pembelajaran di sekolah merupakan serangkaian kegiatan yang secara sadar telah terencana. 
Dengan adanya perencanaan yang baik, akan mendukung keberhasilan pembelajaran.

Perencanaan pembelajaran diupayakan agar proses pembelajaran melibatkan siswa secara aktif sehingga siswa termotivasi yang pada akhirnya mampu mencapai hasil pembelajaran yang telah ditetapkan (Lusidawaty, Fitria, MMiaz, \& Zikri, 2020). Suatu kombinasi yang tersusun, meliputi unsur-unsur manusiawi, material, fasilitas, perlengkapan dan prosedur yang saling mempengaruhi untuk mencapai tujuan pembelajaran di sebut pembelajaran (Aza Nuralita, 2020). Sedangkan tujuan pembelajaran yang hendak dicapai setelah selesai diselenggarakannya suatu proses pembelajaran, yang bertitik tolak pada perubahan tingkah laku siswa (Andayani, Abhi Purwoko, Makhrus, Harjono, \& Kunci, 2020).

Salah satu upaya untuk meningkatkan sumber daya manusia melalui proses pembelajaran disekolah (Warul, 2016). Dalam usaha meningkatkan sumber daya manusia tersebut guru merupakan sumber daya manusia yang harus dibina dan dikembangkan (A. Nugraha, Sutjahjo, \& Amin, 2018; Tompodung, Rushayati, \& Aidi, 2018). Usaha meningkatkan kemampuan guru dalam kegiatan pembelajaran perlu ditingkatkan melalui berbagai kegiatan misalnya: Sertifikasi, Diklat, Workshop dan lain-lain. Kegiatan pembelajaran tidak sekedar mengkomunikasikan pengetahuan agar dapat belajar, tetapi pembelajaran juga berarti usaha membantu siswa agar mampu memahami konsep-konsep dan dapat menerapkan konsep yang telah dipahami. Sehingga dengan pengetahuan yang telah didapat, prestasi belajar siswa juga akan lebih baik. Selain itu, guru juga harus memperbaiki sikap dan melatih keterampilan siswa. Sikap dalam hal ini ialah sikap spiritual dan sikap sosial. Dengan diajarkannya keempat aspek tersebut, maka tujuan pendidikan nasional dapat terwujud.

Sikap spiritual, sosial, pengetahuan dan keterampilan harus diterapkan kepada siswa dalam pembelajaran. Oleh karena itu, guru harus pandai memilih cara atau model pembelajaran yang tepat untuk digunakan dalam pembelajaran. Dalam rangka kegiatan pembelajaran, guru harus menguasai berbagai model pembelajaran. Selain menguasai berbagai model, guru juga harus mampu memilih model pembelajaran yang tepat sesuai materi pelajaran, tingkat kecerdasan siswa, serta lingkungan dan kondisi setempat, kemudian merancang menjadi suatu program pembelajaran yang baik dan tersusun, diperbaiki dan disempurnakan (Harahap \& Sagala, 2019; S. Nugraha, 2019).

Kemampuan guru dalam memilih model pembelajaran yang dipandang dapat membelajarkan siswa melalui proses pengajaran dan membantu para siswanya menguasai model pembelajaran agar siswa belajar secara aktif dan menyenangkan, sehingga tujuan pembelajaran dapat tercapai (Hastuti, Mariyati, Sutarto, \& Nasirin, 2020; Sulfemi \& Mayasari, 2019).

Sebagaimana penjelasan tersebut dapat memberikan pemahaman bahwa salah satu faktor yang mempengaruhi keberhasilan guru dalam melaksanakan pembelajaran adalah ketepatan dalam memilih serta menerapkan model, metode atau strategi pembelajaran yang sesuai dengan materi pelajaran (Felix, Marpaung, Akmal, Psikologi, \& Indonesia, 2019; Tadjuddin et al., 2020). Seperti halnya dalam pembelajaran fisika salah satu alternatif yang dapat di lakukan untuk memperbaiki hasil belajar fisika siswa adalah dengan menerapkan model pembelajaran melalui pendekatan berfikir dan berbasis masalah, yaitu siswa lebih berperan aktif dalam menyelesaikan permasalahan yang dihadapi dalam 
pembelajaran dan diharapkan siswa mendapatkan pengalaman belajar dari proses pembelajaran tersebut. Dalam model pembelajaran melalui pendekatan berfikir dan berbasis masalah, terdapat beberapa model pembelajaran yang dapat diterapkan (Egok, Gurmani, Pendidikan, Sekolah, \& Selatan, 2020; Hendri \& Faradhillah, 2020; N. P. Sari, Suhirman, \& Walid, 2020), salah satu diantaranya adalah Treffinger (Treffinger, 1980).

Berdasarkan Djemari menurut Donald J. Treffinger digagasnya model ini karena perkembangan zaman yang terus berubah dengan cepat dan semakin kompleksnya permasalahan yang harus dihadapi (Huda,2014:318), untuk mengatasi permasalahan tersebut diperlukan suatu cara agar dapat menyelesaikan suatu permasalahan dan mengahasilkan solusi yang paling tepat. Perlu dilakukan untuk mengatasi hal tersebut adalah dengan memberikan fakta-fakta penting yang ada di lingkungan sekitar lalu memunculkan berbagai gagasan dan memilih solusi yang tepat untuk kemudian diterapkan secara nyata (Huda, 2014).

Treffinger menyebutkan bahwa model pembelajaran ini terdiri atas tiga komponen penting (Treffinger, 1980), yaitu Understanding Challenge, Generatif Ideas, dan Preparing for Action, yang kemudian dirinci kedalam enam tahapan (Huda, 2014).

Penjelasan mengenai langkah-langkah model ini sebagai berikut:

1. Komponen 1: Understanding Challenge(Memahami Tantangan)

a. Menentukan tujuan: Guru menginformasikan kompetensi yang harus dicapai dalam pembelajarannya.

b. Menggali data: Guru mendemonstrasikan/menyajikan fenomena alam yang dapat mengundang keingintahuan siswa.

c. Merumuskan masalah: Guru memberikan kesempatan kepada siswa untuk mengidentifikasi permasalahan.

2. Komponen II: Generating Ideas (Membangkitkan Gagasan)

a. Memunculkan gagasan: Guru memberikan waktu dan kesempatan pada siswa untuk mengungkapkan gagasannya dan juga membimbing siswa untuk menyepakati alternatif pemecahan yang akan diuji.

3. Komponen III: Preparing for Action (Mempersiapkan Tindakan)

a. Mengembangkan solusi: Guru mendorong siswa untuk mengumpulkan informasi yang sesuai, melaksanakan eksperimen untuk mendapatkan penjelasan dan pemecahan masalah.

b. Membangun penerimaan: Guru mengecek solusi yang telah diperoleh siswa dan memberikan permasalahn yang baru namun lebih kompleks agar siswa dapat menerapkan solusi yang telah diperoleh.

Adapun manfaat model pembelajaran Treffinger antara lain:

1. Memberi kesempatan kepada siswa untuk memahami konsep-konsep dengan cara menyelesaikan permasalahan .

2. Membuat siswa aktif dalam pembelajaran.

3. Mengembangkan kemampuan berfikir siswa karena disajikan masalah pada awal pembelajaran dan memberi keleluasan kepada siswa untuk mencari arah-arah penyelesaian sendiri.

4. Mengembangkan kemampuan siswa untuk mendefinisikan masalah, mengumpulkan data, menganalisis data, membangun hipotesis, dan percobaan untuk memecahkan suatu permasalahan.

5. Membuat siswa dapat menerapkan pengetahuan yang sudah dimilikinya kedalam situasi baru. 
Sejalan dengan manfaat model pembelajaran Treffinger diatas, maka pada penelitian ini diharapkan dapat memberikan pengaruh yang signifikan terhadap hasil belajar Fisika siswa seperti halnya hasil penelitian yang telah dilakukan oleh beberapa peneliti sebelumnya.

\section{METODE PENELITIAN}

Penelitian ini adalah penelitian kuantitatif. Penelitian kuantitatif adalah metode yang penyajian atau penelitiannya berupa angka-angka dan analisisnya menggunakan statistik (Sugiyono, 2018). Desain penelitian ini menggunakan model pembelajaran Treffinger pada kelas eksperimen dan menggunakan model pembelajaran konvensional pada kelas kontrol. Peneliti sama-sama memberikan tes akhir pembelajaran atau posttes pada kedua kelas tersebut. Adapun yang menjadi variabel dalam penelitian ini adalah:

1. Variabel bebas (independen): model pembelajaran Treffinger.

2. Variabel terikat (dependen): hasil belajar.

Populasi dalam penelitian ini adalah semua siswa kelas VII SMP NU Tebat Jaya Tahun Pembelajaran 2019/2020 yang berjumlah keseluruhan 56 siswa dari 2 kelas yaitu VII A dan VII B. Sedangkan sampel dalam penelitian ini adalah siswa kelas VII SMP NU Tebat Jaya Tahun Pembelajaran 2019/2020 yang berjumlah 56 siswa dibagi menjadi 2 kelas, yaitu kelas VII A siswanya berjumlah 28 siswa, kelas VII B siswanya berjumlah 28 siswa. Sampel tersebut akan diambil secara acak melalui pengundian. Pemilihan kelas eksperimen dan kelas kontrol juga dilakukan secara acak melalui pengundian, yaitu kelas VII A dan VII B.

Bentuk data yang dipakai dalam penelitian ini adalah data berupa hasil belajar siswa, sehingga tekhnik pengumpulan data yang akan digunakan dalam penelitian ini adalah tes. Tes yang digunakan berbentuk pilihan ganda terdiri dari beberapa butir tes (item) yang masing-masing mengukur satu jenis variabel. Pada tes pilihan ganda siswa dituntut adanya ketelitian untuk memilih, karena jawaban hampir sama sehingga dalam hal ini siswa dapat mengembangkan pemikirannya.

Tekhnik pengumpulan data yang digunakan dalam penelitian ini adalah instrumen tes. Tes adalah pertanyaan atau latihan yang digunakan untuk mengukur keterampilan, pengetahuan, intelegensi, kemampuan bakat yang dimiliki oleh individu atau kelompok (Sitaresmi, Saputro, \& Utomo, 2017). Alat ukur yang digunakan harus memenuhi kriteria pengujian terlebih dahulu sebelum diberikan kepada seluruh siswa yang menjadi sampel penelitian. Alat ukur yang digunakan untuk mengumpulkan data harus memenuhi persyaratan yaitu uji validitas, uji realibilitas, uji daya pembeda, dan uji tingkat kesukaran soal agar layak digunakan. Sehingga instrumen tes yang akan digunakan peneliti terlebih dahulu melakukan uji coba pada kelas yang bukan sampel dengan hasil uji coba soal sebanyak 25 butir soal diperolah soal sebanyak 20 butir soal yang layak digunakan.

Selanjutnya setelah semua perangkat pembelajaran dan instrument penelitian telah siap maka dilakukan penelitian. Penelitian dilakukan dikelas eksperimen dan kelas kontrol dengan memberikan tes akhir (posstest). Setelah proses pembelajaran selesai dan pemberian tes sudah dilakukan tahap selanjutnya yaitu menganalisis data dari kedua kelas.

Analisis data penelitian dengan cara membuat daftar distribusi frekuensi, menghitung nilai rata-rata (mean), standar deviasi, dan menentukan kategori tinggi, sedang dan rendah dari nilai tes ahir terhadap hasil belajar fisika siswa pada materi pembelajaran kalor pada 
kelas eksperimen dan kelas kontrol. Datadata tersebut kemudian diuji secara statistik dan ditelaah untuk kemudian dianalisis, dibahas dan disimpulkan hasilnya.

\section{HASIL DAN PEMBAHASAN}

Hasil penelitian yang berupa data kuantitatif terdiri dari hasil belajar fisika siswa pada materi pembelajaran kalor di kelas VII SMP NU Tebat Jaya tahun pembelajaran 2019/2020 baik kelas eksperimen maupun kelas kontrol. Adapun hasil analisis data pada kelas eksperimen dan kelas kontrol adalah sebagai berikut:

1. Berdasarkan perhitungan rekapitulasi hasil tes kelas eksperimen dapat diketahui bahwa nilai tertinggi $=90$ dan nilai terendah $=60$ serta rata-rata nilai siswa kelas VII A SMP NU Tebat Jaya yang pembelajarannya diterapkan model pembelajaran Treffinger adalah 78,36 dengan standar deviasi 8,21.

2. Sedangakan untuk perhitungan rekapitulasi kelas kontrol dapat diketahui bahwa nilai tertinggi $=85$ dan nilai terendah $=50$ serta rata-rata nilai siswa kelas VII A SMP NU tebat Jaya yang pembelajarannya diterapkan model pembelajaran konvensional adalah 66,64 dengan standar deviasi 7,56.

Sedangkan hasil analisis data dari kedua kelas yaitu data kelas eksperimen (data hasil belajar fisika siswa pada materi pembelajaran kalor dikelas VII SMP NU Tebat Jaya tahun pembelajaran 2019/2020 yang pembelajarannya menggunakan model pembelajaran Treffinger) dan data kelas kontrol (data hasil belajar fisika siswa pada materi pembelajaran kalor dikelas VII SMP NU Tebat Jaya tahun pembelajaran 2019/2020 yang pembelajarannya menggunakan model pembelajaran Konvensional) dapat diperoleh perhitungan nilai rata-rata yaitu sebesar 72,47 dengan standar deviasi sebesar 9,35 . Hasil analisis data dari kedua kelas tersebut selanjutnya dijadikan acuan dalam menentukan kategori hasil belajar fisika kedua kelas dengan kategorisasi tinggi, sedang, dan rendah.

Adapun data prosentase yang diperoleh dari hasil belajar fisika siswa ditinjau dari nilai kategori tinggi, sedang, dan rendah disajikan dalam tabel 1 .

Tabel 1. Persentase Hasil Belajar Siswa Setiap Kategori

\begin{tabular}{|c|c|c|c|c|c|c|}
\hline \multirow[t]{2}{*}{ No } & \multirow[t]{2}{*}{ Interval } & \multirow[t]{2}{*}{ Kategori } & \multicolumn{2}{|c|}{$\begin{array}{c}\text { Model Pembelajaran } \\
\text { Treffinger }\end{array}$} & \multicolumn{2}{|c|}{$\begin{array}{c}\text { Model Pembelajaran } \\
\text { Konvensional }\end{array}$} \\
\hline & & & Jumlah Siswa & Prosentase & Jumlah Siswa & Prosentase \\
\hline 1 & $\geq 81,82$ & Tinggi & 8 & $28,57 \%$ & 1 & $3,57 \%$ \\
\hline 2 & $\overline{6} 3,12-81,82$ & Sedang & 19 & $67,86 \%$ & 21 & $75,00 \%$ \\
\hline 3 & $<63,12$ & Rendah & 1 & $3,57 \%$ & 6 & $21,43 \%$ \\
\hline
\end{tabular}

Tabel 1 menunjukkan bahwa hasil belajar Fisika siswa pada materi kalor kelas VII SMP NU Tebat Jaya yang pembelajarannya menggunakan model pembelajaran Treffinger lebih baik dari siswa yang pembelajarannya tanpa menggunakan model pembelajaran Treffinger atau hanya menggunakan model pembelajaran konvensional.

Kemudian untuk menguji seberapa besar pengaruh penerapan model pembelajaran Treffinger terhadap hasil belajar fisika sisiwa pada materi pembelajaran kalor dikelas VII SMP NU Tebat Jaya, dalam penelitian ini terlebih dahulu dilakukan uji prasyarat untuk menganalisis data. Uji prasyarat analisis data dalam penelitian iniyaitu uji normalits data mengunakan rumus Chi Square dan uji homogenitas menggunakan uji-F. 
Perhitungan uji normalitas data pada kelas ekspermen menunjukkan $x_{\text {hitung }}^{2}<x_{\text {tabel }}^{2}$ yaitu $8,99 \leq 11,07$ sehingga dapat disimpulkan bahwa data hasil tes mata pelajaran Fisika siswa pada materi pembelajaran kalor kelas eksperimen yang pembelajarannya menggunakan model pembelajaran Treffinger berdistribusi normal. Sedangkan pada kelas kontrol Hasil perhitungan menunjukkan $x_{\text {hitung }}^{2}<x_{\text {tabel }}^{2}$ yaitu $5,77 \leq 11,07$ sehingga dapat disimpulkan bahwa data hasil tes mata pelajaran Fisika materi pembelajaran kalor kelas kontrol yang pembelajarannya menggunakan model pembelajaran konvensional berdistribusi normal.

Berdasarkan hasil perhitungan data kedua kelas diatas dapat disimpulkan bahwa data kedua kelas tersebut berdisrtribusi normal. Langkah selanjutnya melakukan perhitungan uji homogenitas dengan menggunakan uji-F dengan berdasarkan analisis terhadap tes hasil belajar menunjukkan bahwa nilai varian kedua data adalah sama yaitu 23,50. Sehingga diperoleh perhitungan uji $\mathrm{F}$ adalah 1,00. Setelah diketahui harga Fhitung, kemudian diajukan hipotesis:

$\mathrm{H}_{\mathrm{o}}: \mathrm{S}_{1}^{2}=\mathrm{S}_{2}^{2}$ (varian data homogen).

$\mathrm{H}_{\mathrm{a}}: \mathrm{S}_{1}^{2} \neq \mathrm{S}_{\mathrm{s}}^{2} \quad$ (varian data tidak homogen).

Kriteria uji homogenitas $\mathrm{H}_{\mathrm{o}}$ ditolak jika $F_{\text {hitung }}>\mathrm{F}_{\text {tabel }}(0,05 ; \mathrm{dk} 1 ; \mathrm{dk} 2)$ dan $\mathrm{H}_{\mathrm{o}}$ diterima jika $F_{\text {hitung }} \leq F_{\text {tabel }(0,05 ; \mathrm{dk} 1 ; \mathrm{dk} 2)}$ serta besarnya $\alpha$ diambil $5 \%$. Berdasarkan nilai $F_{\text {tabel }}$ pada lampiran 25 dapat dilihat bahwa $F_{\text {hitung }}<F_{\text {tabel }}$ yaitu $1,00<1,88$. Dengan demikian dapat disimpulkan bahwa varian dalam penelitian ini adalah homogen.

Setelah data diketahui terdistribusi normal dan homogen untuk menguji hipotesis menggunakan uji $-\mathrm{t}$. Berdasarkan perhitungan hasil uji $t$ diperoleh harga $t_{\text {hitung }}$ sebesar $=5,45$.
Setelah diketahui nilai $t_{\text {hitung, langkah }}$ selanjutnya adalah menentukan nilai $t_{\text {tabel }}$ yang dapat dilihat pada lampiran 26 dengan taraf signifikansi $5 \%$ atau interval kepercayaan $95 \%$ dengan $\mathrm{db}=\left(\mathrm{N}_{1}+\mathrm{N}_{2}-\right.$ $2)=28+28-2=54$. Oleh karena pada tabel $\mathrm{t}$ tidak ditemukan db 54, maka dilakukan perhitungan menggunakan interpolasi.

Berdasarkan hasil perhitungan interpolasi dapat diketahui bahwa nilai $t_{\text {tabel }}$ untuk df $28+28-2=54$ adalah 1,99. Kriteria pengujian hipotesis yaitu terima $\mathrm{H}_{0}$ apabila $-\mathrm{t}_{\text {tabel }} \leq \mathrm{t}_{\text {hitung }} \leq \mathrm{t}_{\text {tabel }}$ dan tolak $\mathrm{H}_{0}$ jika thitung tidak terdapat diantara $-t_{\text {tabel }}$ dan $t_{\text {tabel }}$. Oleh karena $t_{\text {hitung }}$ 5,45 tidak terletak diantara $-t_{\text {tabel }}$ dan $t_{\text {tabel }}$ yaitu -1,99 dan 1,99 maka dapat disimpulkan tolak $\mathrm{H}_{0}$ dan terima $\mathrm{H}_{\mathrm{a}}$. Oleh karena itu dapat disimpulkan bahwa terdapat pengaruh model pembelajaran Treffinger yang signifikan terhadap hasil belajar Fisika siswa pada materi pembelajaran kalor di kelas VII SMP NU Tebat Jaya Tahun Pembelajaran 2019/2020.

Temuan pada penelitian ini mendukung beberapa penelitian sebelumnya bahwa penggunaan model pembelajaran Treffinger dapat memberikan pengaruh yang signifikan terhadap berpikir kritis (Y. I. Sari \& Putra, 2015), hasil belajar siswa (Rosiyanti \& Wijayanti, 2015), kreativitas siswa (Rahmawati \& Kurniawan, 2015). Temuan penelitian ini mendukung penelitian rosyianti, wijayanti (2015). Adanya penelitian ini diharapkan dapat meningkatkan mutu dan kualitas pendidikan di Indonesia terutama pada hasil belajar siswa. Rekomendasi penelitian selanjutnya untuk mengintegrasikan model treffinger dengan model yang lain.

\section{SIMPULAN DAN SARAN}

Berdasarkan analisis data dan pembahasan hasil penelitian dapat ditarik 
kesimpulan yaitu terdapat pengaruh penerapan model pembelajaran Treffinger yang signifikan terhadap hasil belajar Fisika siswa pada materi pembelajaran kalor di kelas VII SMP NU Tebat Jaya Tahun Pembelajaran 2019/2020 dengan nilai $t_{\text {hitung }} 5,45$ dan $t_{\text {tabel }} 1,99$.

Berdasarkan hasil penelitian tersebut disarankan guru hendaknya dapat menerapkan model pembelajaran Treffinger dalam pembelajaran Fisika agar siswa lebih kreatif dalam menyelesaikan berbagai permasalahan yang berhubungan dengan materi pembelajaran dan berimplikasi pada pencapaian hasil belajar secara maksimal. Untuk siswa hendaknya dapat berperan aktif dalam pembelajaran dengan melaksanakan instruksi guru sesuai langkah-langkah pembelajaran menggunakan model pembelajaran Treffinger agar dapat memahami materi pembelajaran dengan baik. Untuk sekolah hendaknya dapat menginstruksikan para gurunya agar menerapkan berbagai metode pembelajaran inovatif seperti model pembelajaran Treffinger sehingga dapat meningkatkan kualitas pembelajaran

\section{DAFTAR PUSTAKA}

Andayani, Y., Abhi Purwoko, A., Makhrus, M., Harjono, A., \& Kunci, K. (2020). Identifikasi Pemahaman Guru Tentang Pengembangan Perangkat Pembelajaran IPA SMP dengan Pendekatan Etnosain. Jurnal PEPADU, 1(2), 229-234. Retrieved from

http://jurnal.lppm.unram.ac.id/index. php/jurnalpepadu

Aza Nuralita. (2020). Analisis penerapan model Pembelajaran berbasis etnosains dalam pembelajaran tematik SD. MIMBAR PGSD Undiksha, 4(1), 1-8.

Dameron, M. L., Camp, A., Friedmann, B., \& Parikh-foxx, S. (2020).
Multicultural Education and Perceived Multicultural Competency of School Counselors. Multicultual Counseling and Development, 48(July), 176-190. https://doi.org/10.1002/jmcd.12176

Egok, A. S., Gurmani, G., Pendidikan, P., Sekolah, G., \& Selatan, S. L. S. (2020). Development of Etnosains Materials in 5E Cycle Learning Model Based on the Local Culture of Primary School Students. Journal of Educational Research and Evaluation, 9(1), 22-30.

Felix, T., Marpaung, W., Akmal, M. El, Psikologi, F., \& Indonesia, U. P. (2019). Peranan Kecerdasan Emosional Pada Pemilihan Strategi Coping Pada Mahasiswa yang Bekerja. Persona: Jurnal Psikologi Indonesia, 8(1), 39-56.

Harahap, D. A. F., \& Sagala, E. J. (2019). Pengaruh Kecerdasan Emosional terhadap Kesiapan Kerja pada Mahasiswa Paramedic. Akuntabel, 16(1), 47-53.

Hastuti, I. D., Mariyati, Y., Sutarto, \& Nasirin, C. (2020). The Effect of Guided Inquiry Learning Model to the Metacognitive Ability of Primary School Students. Prisma Sains: Jurnal Pengkajian Ilmu Dan Pembelajaran Matematika Dan IPA IKIP Mataram, 8(1), 37-45.

Hendri, S., \& Faradhillah. (2020). Pengembangan Lembar Kerja Siswa Listrik Dinamis (LKS) Berbasis Inkuiri. IJIS Edu: Indonesian J. Integr. Sci. Education, 2(1), 1-6.

Huda, M. (2014). Model-Model Pengajaran dan Pembelajaran IsuIsu Metodis dan Paradigma. Yogyakarta: Pustaka Pelajar.

Izzah, S. N., Sudarmin, Prasetyo, A. P. B., \& Wiyanto. (2020). The Development of Science Learning Document Grounded on STEMApproach Integrated Ethnoscience. Advances in Social Science, 
Education and Humanities Research, 443(Iset 2019), 554-558.

Lusidawaty, V., Fitria, Y., MMiaz, Y., \& Zikri, A. (2020). Pembelajaran IPA dengan Strategi Pembelajaran Inkuiri untuk Meningkatkan Keterampilan Proses Sains dan Motivasi Belajar Siswa Di Sekolah Dasar. Jurnal Basicedu, 4(1), 168174.

Nugraha, A., Sutjahjo, S. H., \& Amin, A. A. (2018). Persepsi dan Partisipasi Masyarakat Terhadap Pengelolaan Sampah Rumah Tangga melalui Bank Sampah di Jakarta Selatan. Jurnal Pengelolaan Sumberdaya Alam Dan Lingkungan, 8(1), 7-14. https://doi.org/10.29244/jps1.8.1.714

Nugraha, S. (2019). Kecerdasan Emosional dan Perilaku Kewarganegaraan Organisasi pada Pegawai Badan Kepegawaian Daerah. Business Innovation and Entrepreneurship Journal, 1(1), 6267. Retrieved from https://doi.org/10.35899/biej.v1i1.3

Rahmawati, L., \& Kurniawan, E. S. (2015). Pengaruh Model Pembelajaran Treffinger Terhadap Kreativitas dan Hasil Belajar Suhu dan Kalor Siswa Kelas X SMA Negeri 3 Purworejo Tahun Pelajaran 2014 / 2015, 7(1), 26-31.

Rosiyanti, H., \& Wijayanti, E. (2015). Implementasi Model Pembelajaran Treffinger Terhadap Hasil Belajar Matematika dan Sikap Siswa. Jurnal Pendidikan Matematika, 1(2), 3744.

Sari, N. P., Suhirman, S., \& Walid, A. (2020). Pengembangan Modul Pembelajaran IPA Berbasis Etnosains Materi Interaksi Makhluk Hidup dengan Lingkungannya untuk Menanamkan Jiwa Konservasi Siswa Kelas VII SMP. Bio-Edu: Jurnal Pendidikan Biologi, 5(2), 6374. https://doi.org/10.32938/jbe.v5i2.55

4

Sari, Y. I., \& Putra, D. F. (2015). Pengaruh Model Pembelajaran Treffinger Terhadap Kemampuan Berpikir Kritis dan Kreatif Mahasiswa Universitas Kanjuruhan Malang. Jurnal Pendidikan Geografi, 20(2), 30-38.

Seifan, M., Robertson, N., \& Berenjian, A. (2020). Use of virtual learning to increase key laboratory skills and essential non-cognitive characteristics. Education for Chemical Engineers, 33, 66-75. https://doi.org/10.1016/j.ece.2020.07 .006

Sitaresmi, K. S., Saputro, S., \& Utomo, S. B. (2017). Penerapan Pembelajaran Project Based Learning (PjBL) untuk Meningkatkan Aktivitas dan Prestasi Belajar Siswa pada Materi Sistem Periodik Unsur (SPU) Kelas X MIA 1 SMA Negeri 1 Teras Boyolali Tahun Pelajaran 2015/2016. Jurnal Pendidikan Kimia, 6(1), 54-61. Retrieved from http://jurnal.fkip.uns.ac.id/index.php /kimia/article/view/9405

Sugiyono. (2018). Metode Penelitian Kuantitatif, Kualitatif dan $R \& D$. bandung: Penerbit Alfabeta.

Sulfemi, W. B., \& Mayasari, N. (2019). The Use of Audio Visual Media in Value Clarification Technique to Improve Student Learning Outcomes in Social Studies. Jurnal Pendidikan, 20(1), 53-68.

Tadjuddin, N., Robingatin, Meriyati, Hadiati, E., El-Fiah, R., Walid, A., \& Widayanti. (2020). Emotional Intelligence of Elementary Scholar: Instructional Strategy and Personality Tendency. European Journal of Educational Research, 9(1), 203-213. https://doi.org/10.12973/eujer.9.1.203 
Tompodung, T. C. G., Rushayati, S. B., \& Aidi, M. N. (2018). Efektivitas Program Adiwiyata Terhadap Perilaku Ramah Lingkungan Warga Sekolah Di Kota Depok. Jurnal Pengelolaan Sumberdaya Alam Dan Lingkungan, $\quad 8(2), \quad 170-177$. https://doi.org/10.29244/jpsl.8.2.170 $-177$

Treffinger, D. J. (1980). Encouraging Creative Learning For The Gifted And Talented. Ventura. California: Ventura County Schools/LTI.
Undang-Undang Republik Indonesia. (2003). Undang-undang Republik Indonesia Nomor 20 Tahun 2003. Undang-Undang Sistem Pendidikan Nasional. Retrieved from http://stpibinainsanmulia.ac.id/wpcontent/uploads/2013/04/Lamp_2_U U20-2003-Sisdiknas.doc

Warul, W. (2016). Arah Pengembangan Sumberdaya Manusia Dalam Dimensi Pendidikan Islam. Jurnal Edukasi, 2(July), 147-163. 